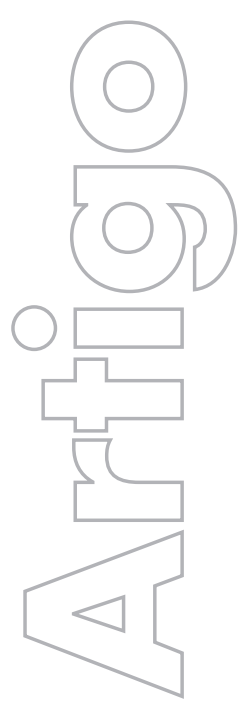

revista

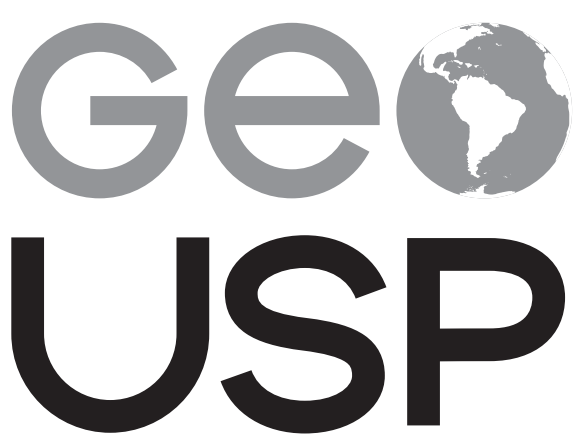

espaço e tempo

Volume $20 \cdot n^{\circ} 2(2016)$

ISSN 2179-0892

\section{Sustentabilidade na} agricultura familiar e a influência dos atores regionais: estudo de caso da região de Parauapebas-PA

Neli Aparecida de Mello-Théry EACH-USP

Camila Ferreira Leite EACH-USP

p. $295-311$

Como citar este artigo:

MELLO-THÉRY, N. A.; LEITE, C. F. Sustentabilidade na agricultura familiar e a influência dos atores regionais: estudo de caso da região de Parauapebas-PA. Geousp - Espaço e Tempo (Online), v. 20, n. 2, p. 295-311, mês. 2016. ISSN 2179-0892.

Disponível em: <http://www.revistas.usp.br/geousp/issue/ view/6465>. doi: http://dx.doi.org/10.11606/issn.2179-0892. geousp.2014.84539.

\section{(c) $(1) \Theta$}

Este artigo está licenciado sob a Creative Commons Attribution 4.0 License. 


\title{
Sustentabilidade na agricultura familiar e a influência dos atores regionais: estudo de caso da região de Parauapebas-PA
}

\section{Resumo}

Este texto analisa o papel dos atores regionais na sustentabilidade da agricultura familiar da área de proteção ambiental do Igarapé Gelado, tomando como base os resultados do programa Duramaz-1 (Determinantes do Desenvolvimento Sustentável na Amazônia), e atualiza alguns dados dessa experiência. Entre 2009 e 2013, com a mudança de função de alguns atores, a situação evoluiu, resultando no êxito da produção agrícola sustentável e do extrativismo de frutos nativos para um pequeno grupo, enquanto a maioria dos moradores da APA se vê privada de tais iniciativas, seja por desinteresse ou por dependência e falta de empoderamento, exclusão ou dificuldade financeira, reduzindo a possibilidade de ampliação desse tipo de ação, fatores que potencialmente ameaçam a produção sustentável em uma APA.

Palavras-chave: Agricultura sustentável. Atores. Conflito. Cooperativa. Influência.

\section{Sustentability of family farming and the influence of regional actors: the case of Parauapebas region-PA}

\begin{abstract}
This paper analyzes the role of regional actors in the family farming sustainability of the lgarape Gelado's Environmental Protection Area, using the results of Duramaz-1 as base as well as analyzing and updating some data of this experience concerning local sustainability. A different situation was found between 2009 and 2013 with a modified relationships and new functions of some actors resulting in the success of sustainable agricultural production and extraction of native fruits to a small group succeeds while most residents of the APA is deprived of such initiatives. This is because of lack of interest or dependency and lack of empowerment, exclusion, financial difficulties, minimizing the possibility of expanding of this practices. Factors potentially threaten the sustainable production.
\end{abstract}

Keywords: Sustainable agriculture. Actors. Conflict. Cooperative. Influence. 


\section{Introdução}

"A análise do processo de sustentabilidade representa um grande desafio científico enquanto a Amazônia constitui um verdadeiro laboratório" (Droulers et al., 2011). É dentro foi nesse contexto que se desenvolveu o projeto de pesquisa Duramaz-1 (Déterminants du Développement Durable en Amazonie Brésilienne - Determinantes do Desenvolvimento Sustentável na Amazônia) e no qual se baseou esta iniciação científica.

A pesquisa Duramaz-1 analisou os determinantes que condicionam o êxito ou o fracasso de experiências voltadas para o desenvolvimento sustentável na região amazônica e para isso criou um sistema de indicadores visando medir a sustentabilidade de situações locais, identificadas como 13 experiências sustentáveis,' implantadas em quatro eixos distintos (extrativismo, agricultura familiar, agronegócio e território indígena), e, principalmente, a relacioná-las, buscando encontrar os elementos condicionantes e determinantes da sustentabilidade.

Usados como base de mensuração de situações e representação da realidade, indicadores são ferramentas:

[...] fundamentais para tomadores de decisão e para a sociedade, pois permitem tanto criar cenários sobre o meio, quanto aferir ou acompanhar os resultados de uma decisão tomada. São indicativos das mudanças e condições no ambiente e, se bem conduzidos, permitem representar a rede de causalidades presente num determinado meio (Santos, 2004, p. 60).

Duramaz-1 desenvolveu um sistema próprio de indicadores para o estabelecimento do nível de sustentabilidade, totalizando 44 subindicadores em quatro aspectos da sustentabilidade (condições de vida, proteção do meio ambiente, organização social e necessidades do presente e perspectivas futuras). Considerou a sustentabilidade como a habilidade de manter as condições ambientais, conservando o equilibrio e a qualidade ambiental, sendo esta influenciada direta e indiretamente pelas forças econômicas, sociais e ambientais atuantes. Metodologicamente, adotaram-se duas técnicas: (i) o questionário sobre condições de vida e a retrospectiva biográfica dos líderes, cujos resultados serviram para modelar cenários, e (ii) um modelo teórico da influência dos indicadores, assim como os elementos comuns identificados nas experiências de desenvolvimento sustentável.

Esses resultados serviram de base para um novo projeto de pesquisa (Duramaz-2), que continuou a análise das experiências visando criar um modelo teórico da sustentabilidade, incluindo novas questões que envolviam mudança de clima, biodiversidade, avaliação institucional e outros fatores internos e externos nos locais estudados. Aplicou resultados de modelagem para fundamentar uma teoria da sustentabilidade no contexto das florestas tropicais e, portanto, na produção de cenários de evolução dos locais estudados.

Assentada nas premissas dessa pesquisa, o projeto de iniciação científica integrou-se ao contexto geral, objetivou compreender alguns aspectos da realidade vivida por atores regionais em 2013 e analisar o papel destes na sustentabilidade da agricultura familiar da APA.

\footnotetext{
Além da própria autoclassificação, a principal premissa para identificar as experiências de desenvolvimento sustentável foi o financiamento com recursos oriundos de doações ou empréstimos internacionais e/ou do orçamento nacional em decorrência do tema, da origem da ideia ou da inserção das três dimensões de sustentabilidade, do modelo organizativo dos projetos, os quais representavam diferenciais em relação a projetos tradicionais.
} 
Este artigo é estruturado em cinco partes, a primeira delas de contextualização da APA, abordando os fatores e forças atuantes no momento de sua criação e institucionalização. A segunda parte indica os materiais e métodos utilizados. A terceira aborda os atores regionais e analisa seu papel e sua influência na sustentabilidade. A quarta aborda os projetos indicados pelo Duramaz-1 como emblemáticos da sustentabilidade da agricultura local e faz alguns questionamentos. A quinta parte destaca a percepção da sustentabilidade segundo a pesquisa Duramaz-1 apresentando os indicadores mais relevantes adotados na análise e as conclusões.

\section{Contextualização da APA}

Com uma área de 21.600 ha, a APA Igarapé Gelado, localizada no município de Parauapebas, sudeste do Pará, faz parte do mosaico de áreas protegidas formado por cinco unidades de conservação que juntas perfazem 1,23 milhões de hectares. Forma o último remanescente de floresta contínua na região. Esse grande cinturão verde foi estrategicamente criado pela Secretaria Especial de Meio Ambiente (Sema) (antecessora do Ibama) a fim de evitar conflitos de terra e proteger as áreas que cercam a província mineral da Serra dos Carajás, explorada pela Vale² (Mello-Théry; Théry, 2009; Le Tourneau; Droulers, 2010): "De fato, é possível entender a instituição das áreas de conservação já como zonas de amortecimento, protetoras da atividade mineradora" (Aquino, 2006, p. 93).

Criada em 1989, pelo Decreto n. 97.718, a APA é a única unidade de conservação (UC) do mosaico que permite uso agrícola. Segundo o Sistema Nacional de Unidades de Conservação (Snuc), as áreas de proteção ambiental:

[... têm como objetivos básicos manter a diversidade biológica, disciplinar o processo de ocupação e assegurar a sustentabilidade dos recursos naturais, de forma que a exploração e o uso dos recursos não sejam predatórios e impactantes ao meio ambiente e às populações humanas que deles dependem (Snuc, 2000).

Devido à baixa densidade demográfica e econômica regional, o governo federal impulsionou diversos projetos desde os anos 1970. Para tornar a região atrativa, foram cruciais o Programa de Integração Nacional (PIN), que tinha como referência a construção de grandes rodovias, visto como o primeiro ponto notável no processo de ocupação da Amazônia; o Programa de Polos Agropecuários e Agrominerais da Amazônia (Polamazônia), criado em 1974, que já incluía o Polo de Carajás, ao qual se somou, em 1985, o Programa Grande Carajás (PGC).

Na região da Serra dos Carajás, o eixo central do PGC foi estabelecer infraestrutura e atrair investimentos, instituindo-se numa tentativa do governo para:

[...] coordenar a execução, de forma mais ágil, de projetos já existentes na área e de estimular a modernização da região. $\bigcirc$ PGC passou, então, a receber aporte de mais de 1/4 dos fundos públicos destinados à Amazônia (Monteiro; Coelho, 2004, p. 111). 
Segundo Mello-Théry e Théry (2009, p. 75), as estratégias governamentais e as ações pautavam-se na implantação de projetos de colonização agrária, mas, ao mesmo tempo, o Estado "abdicou de seu papel de defensor de todos os segmentos sociais, concentrando-se no atendimento aos grupos mais organizados e de maior poder", como é o caso da companhia Vale.

Em uma década, o governo federal inclui em suas estratégias a implantação de políticas de auxílio à agricultura familiar em todo o Brasil: "Na escala regional, esta política toma a forma da regularização fundiária das terras dos pequenos agricultores e serve de apoio a alguns tipos de atividades" (Mello-Théry; Théry, 2009, p. 77). Muitos desses pequenos agricultores vivem na APA Igarapé Gelado. São antigos garimpeiros que migraram para lá quando o garimpo de Serra Pelada foi interditado.

Apesar disso, são grupos privados, em especial a Vale, e grupos associativos que dispõem de mais recursos e influenciam as ações regionais de estímulo aos produtores e ao desenvolvimento local.

Ao mesmo tempo em que a Vale concentra forte poder político e econômico na região, influenciando o aparato estatal em alguns aspectos no que tange à gestão da APA, a sociedade civil começou a se organizar, em particular, os agricultores que passaram a se mobilizar "para fazer alguma coisa por eles mesmos", além da regularização fundiária, e criaram associações e cooperativas para fomentar a produção (Muchagata, 2004, p. 251).

Diversos atores influenciam as dinâmicas locais e regionais e sua atuação é relevante no contexto da produção agrícola da APA. De acordo com o sistema Duramaz-1, um total de 16 atores, entre eles, poder público, empresas privadas, $\mathrm{ONG}$, grupos religiosos e sociedade civil organizada, intervêm na APA, direta ou indiretamente, em nível local, regional, nacional ou internacional. $\bigcirc$ desenvolvimento sustentável na APA Igarapé Gelado depende, contudo, de três atores principais: a Cooperativa Mista dos Produtores Rurais (Cooper), a Prefeitura Municipal de Parauapebas e a Vale. Embora a gestão da APA seja de responsabilidade do Instituto Chico Mendes de Conservação da Biodiversidade (ICMBio), essa instituição é mais uma articuladora, que procura integrar os recursos (Vale), a expertise (Cooper) e as ações de acesso ao mercado local (prefeitura).

Além dos atores regionais de relevância, o Duramaz-1 aponta dois projetos emblemáticos ao desenvolvimento sustentável da APA, os quais indicam a aposta na produção local e comercialização dos frutos nativos como caminho da sustentabilidade local. Um deles é a criação da já citada Cooper, e o outro é o Projeto Alternativo ao Desmatamento e Queimada (Padeq), ambos financiados pelo PPG7 (Programa Piloto de Proteção das Florestas Tropicais Brasileiras), subprograma PD/A Projetos Demonstrativos Tipo A, no final dos anos 1990.

\section{Materiais e métodos}

Os resultados aqui apresentados se apoiam na seguinte orientação metodológica:

- levantamento bibliográfico objetivando analisar o panorama geral da situação local em 2009 incluindo os projetos vigentes, a atuação de cada um dos atores e o contexto social, econômico e ambiental da APA (Droulers et al., 2001; Le Tourneau; Droulers, 2010; Mello; Van Tilbeurg, 2009; Marchand, 2010);

- da mesma maneira, as conclusões da pesquisa Duramaz-1 constituintes do livro L'Amazonie brésilienne et le développement durable (Le Tourneau; Droulers, 2010) serviram como referência para a interpretação; 
- análise das políticas públicas que incidem nesta região amazônica e suas repercussões locais.

Nos procedimentos investigativos e técnicos foram adotados: (a) pesquisa documental, (b) entrevistas semiestruturadas, (c) visita de campo, (d) representações gráficas e cartográficas e (e) fotos.

A ida a campo colheu as mesmas informações em 2013, para estabelecer um novo panorama, verificar o que se manteve e o que mudou desde 2009 (Duramaz-1) e detectar os fatores causadores das mudanças observadas. Para tal, elaborou-se um roteiro de perguntas para as entrevistas semiestruturadas, sendo algumas delas as mesmas realizadas em 2009, estabelecendo diálogo com diversos atores locais, entre eles, funcionários da Vale, do ICMBio, da Secretaria Municipal da Produção e de Desenvolvimento Rural (Sempror) e da Cooper, além de 23 produtores familiares residentes na APA e o presidente e tesoureiro da Aproapra, ele mesmo um produtor. Com base nas entrevistas, descrevem-se o papel e a atuação dos principais atores relacionados à produção agrícola baseada em sistemas agroflorestais (SAF), quanto ao ideário do desenvolvimento sustentável local. Essa análise será complementada com base na Lei n. 9.985 (Snuc, 2000) e no Programa de Boas Práticas Agropecuárias da Embrapa.

\section{O papel dos atores regionais: resultados e discussões}

Escolheu-se abordar os três principais atores listados pelo Duramaz-1 como responsáveis pela sustentabilidade local. Para estudá-los, descrevem-se o papel e a atuação de cada um deles, que se analisam e reinterpretam com base em informações e dados atuais, obtidos no decorrer do trabalho de campo.

\section{Cooper}

Criada para estimular o associativismo de produtores com a produção de frutas regionais em SAF e reduzir a variação de preços, a dependência e a vulnerabilidade da produção, a Cooper (Cooperativa Mista dos Produtores Rurais da Região de Carajás) reúne produtores regionais para a produção e comercialização de polpas de frutas, bombons e outros subprodutos, tendo sido considerada o principal ator na operacionalização da sustentabilidade da APA pelo Duramaz-1. Além de ator principal, sua criação foi considerada emblemática para a sustentabilidade, uma vez que não só estimulou a produção, mas representou um potencial avanço no sentido de conceber um mecanismo de valorização dos produtos locais e de redução da vulnerabilidade da produção, mas também ensejou maior organização, articulação, autonomia e empoderamento dos produtores.

Em 2007, a Cooper tinha 69 afiliados, e, enquanto triplicaram sua estrutura e produção, agregaram-se somente mais cinco sócios, totalizando 74 filiados, dos quais apenas 12 (de um total de 120) produtores são da APA (informação verbal). ${ }^{3}$ Assim, 10\% dos produtores da APA representam 16\% dos associados da Cooper. Ao mesmo tempo, o processo de afiliação

3 Informação fornecida por Mauro Melo da Silva, presidente da cooperativa, em entrevista realizada no dia 20 de janeiro de 2013, na sede da Cooper, em Parauapebas. 
tornou-se mais rigoroso, dificultando a entrada de novos membros. Antes, a taxa de filiação era $R \$ 415,00$, subindo, em 2013, para $R \$ 1.900,00$. Além disso, o candidato a sócio deve ter o perfil "adequado" à cooperativa, trabalhar com fruticultura, ser apresentado por três associados e ainda aprovação em eleição na Assembleia.

Embora os procedimentos para aceite de novos cooperados tenham sido estabelecidos pelos integrantes da Cooperativa, fica evidente a dificuldade de acesso. Segundo o presidente, isso ocorre porque se prioriza a qualidade, e não a quantidade, de modo que é preferível ter poucos e bons sócios, cuja produção seja alta. Por outro lado, apesar dessa dificuldade, os produtores têm mais autonomia, podendo optar não se vincular à Cooper.

Em 2007, a Cooper representava uma alternativa relevante para a dependência e a vulnerabilidade da produção ao mercado consumidor, mantendo valores de compra estáveis e fixos, que não oscilavam com a oferta e a demanda, e se dispondo a comprar perdas de produção como forma incentivar o produtor. Atualmente, frente à intensa dinâmica da região de Parauapebas e à crescente demanda de alimentos, os produtores não encontram dificuldades para vender seus produtos, de modo que a Cooper perdeu esse caráter de manutenção da segurança frente à garantia de venda. Além disso, ela deixou de ser um mercado atrativo, já que a feira e o atravessador (intermediário) pagam melhor do que a cooperativa. Diferente do que foi apontado em 2007, em 2013, o mercado municipal é farto e não representa fator de dependência dos produtores, já que a região tem grande demanda, dado o déficit de alimentos. ${ }^{4}$

A Cooper é vantajosa para os associados, já que dá incentivos à plantação, fornece equipamentos, assistência técnica, transporte e adubo. Articula também diversas parcerias, entre elas, um convênio com a Fecat (Federação das Cooperativas da Agricultura Familiar do Sul do Pará) em associação com a Embrapa para solucionar o problema da doença chamada "vassoura de bruxa" nos cupuaçuzeiros e outra com a Petrobras no contexto do programa de fruticultura com SAF. Os associados também recebem empréstimos e financiamentos para a produção e participação nos lucros.

Assim, tanto para a Cooper como para o município de Parauapebas, faltam produtos. Houve uma queda geral da produtividade devido o empobrecimento do solo (parcialmente ligada à mecanização que substituiu as queimadas), aumento do calor e redução de chuvas, ao mesmo tempo em que a demanda não para de crescer frente ao acelerado crescimento de Parauapebas (15,46\% entre 2007 e 2010, segundo o IBGE). ${ }^{5}$ Quando o preço, a feira municipal paga melhor e os produtores optam por ela. Produtores de outros locais como Curionópolis, Eldorado de Carajás e Canaã dos Carajás não precisam ser cooperados para fornecer para a Cooper. Desde 2003, fazem parte da rede de comercialização criada pela Fecat e entendem que não existe mercado tão bom como Parauapebas. Entretanto, na entressafra a cooperativa se vê obrigada a buscar produção ainda mais longe, em Petrolina (BA), o que não se verificava antes.

Sendo a principal função das cooperativas:

[...] servir de intermediárias entre o mercado e as economias dos cooperados, para promover o seu incremento", de forma a contribuir para o crescimento de cada um individualmente, do grupo e da comunidade (Simioni et al., 2009).

\footnotetext{
4 Segundo a Sempror, no ano de 2011, o consumo médio diário da população foi de 193 t, e apenas 6 t eram produzidas na região.

5 Fato confirmado pelos produtores da APA, pelo ICMBio e pela Sempror, relatados em entrevista.
} 
A Cooper exerce bem tal função, a despeito de beneficiar um grupo reduzido. A relevância da Cooper resulta da medida em que representa um espaço altamente organizado e articulado com outros atores regionais, com elevada capacidade de estimular a produção e tornar essa parcela da sociedade até então marginalizada mais autônoma, articulada e empoderada.

\section{Vale}

A experiência de desenvolvimento sustentável na APA se inscreve no contexto de uma área que abriga a maior província mineral do estado do Pará, sob concessão da Vale, o que torna a produção mineral a principal atividade econômica da região. Tendo a exploração direta dos recursos naturais como base econômica, essa empresa representa forte potencial impactante ao meio ambiente.

Para Mello e Van Tilbeurgh (2009), grupos privados como esse têm papel fundamental para consolidar numerosas ações regionais de qualquer tipo, em qualquer tema, direta ou indiretamente, por meio de suas fundações. Segundo o Duramaz-1, a Vale é importante por estar envolvida na criação de projetos, como o Padeq ou o Projeto Açaí, e por investir em logística e infraestrutura, como via férrea, porto, estradas e poços, tornando-se um ator central no desenvolvimento regional.

Quanto à gestão de UC pelo Instituto Chico Mendes de Conservação da Biodiversidade (ICMBio), ${ }^{6}$ a APA, assim como as demais unidades de conservação regionais, contam com o apoio integral da Vale. A empresa fornece brigada de incêndio, guarda florestal, moradia e cota de combustível ao ICMBio. De acordo com o gestor e moradores da APA, a Vale colabora com infraestrutura somente quando há pedido e cobrança, ou quando é necessário para a própria Companhia, como é o caso da manutenção da via férrea e do porto abordados em Le Tourneau; Droulers, 2010).

Sempre que há um projeto impactante existem compensações que visam melhorar as condições de vida local. Como exemplo, no ano de 2007 a Vale alagou diversos açaizais com o alteamento da barragem do Rio Gelado e para remediar o impacto foi criado o Projeto Açaí para repor a mesma quantidade de açaizal perdida, fornecendo espécies de açaí anão (OGM) para alguns produtores. No entanto, questões sobre o risco social e ambiental de inserir uma espécie OGM numa área de proteção não foram e nem são respondidas.

Para fomentar o desenvolvimento local, a Fundação Vale (FV) incentiva a sustentabilidade e fomenta o desenvolvimento regional, com foco na produção e educação. No campo da educação, eliminou as escolas multisseriadas e construiu um complexo educacional que obteve em 2012 a melhor média de desempenho no Índice de Desenvolvimento da Educação Básica (Ideb) da zona rural do Pará. No âmbito da saúde não há nenhuma iniciativa, mas em casos de emergência há suporte da Vale no hospital do Núcleo Urbano de Carajás.

Também criou em 2008 a Estação Conhecimento (EC) na APA Igarapé Gelado, centro promotor de estímulo à produção, comercialização e beneficiamento do leite e à educação participativa e inclusiva. Constituída como uma Organização da Sociedade Civil de Interesse

6 Antes de 2007, a responsabilidade era do Instituto Brasileiro do Meio Ambiente e dos Recursos Naturais Renováveis (lbama). 
Público (Oscip), a EC é fomentada pela FV, que investiu $R$ \$20.727.558,00 até o fim de 2012, e viabilizada por meio de parcerias locais com o poder público e a comunidade. Fazem parte dessa Oscip a Associação dos Produtores da APA Igarapé Gelado (Aproapra), a Associação Filhos da Terra, a Secretaria de Educação de Parauapebas (Semed), o ICMBio e a Prefeitura Municipal de Parauapebas via Sempror.

A EC promoveu diversos cursos, como por exemplo de empreendedorismo e de finanças, oferecidos à Fundação para a Infância e Adolescência (FIA) e abertos a todos, e outros com enfoque específico nos projetos desenvolvidos, como de manejo do açaí, exclusivo aos beneficiários do Projeto Açaí.

Também criou diversos projetos para estimular a produção, que atingiram parte dos produtores e tinham como requisito seu grau de participação, dedicação e aptidão, considerando seu histórico na região. Além disso, os produtores não poderiam ter parcelado e vendido a terra e nem estar em litígio com o ICMBio devido à queima ilegal.

Um dos projetos em andamento é o de piscicultura que forneceu tanque escavado, rede e 8000 alevinos, além de ração de engorda durante o primeiro ano. Até o início de 2013 o projeto beneficiou 11 produtores da APA.

A principal iniciativa da EC foi o desenvolvimento da bovinocultura, demanda dos produtores da APA. Esse projeto atendeu 53 produtores selecionados por aptidão ${ }^{7}$ e forneceu sete matrizes da espécie Girolando, cerca elétrica, pastagens, curral e cursos (inseminação artificial, manejo do gado etc.). Os machos ficam na EC e fazem rodízio para cruzar com as fêmeas.

Segundo o Snuc, ${ }^{8}$ atividades agropecuárias são aceitáveis enquanto não tiverem potencial de degradação ambiental. Desse modo, a bovinocultura foi pensada como sustentável e não degradante, fazendo uso de áreas já desmatadas e realizada de modo semi-intensivo: tem pastagem rotacional de três hectares e uma área de plantação de cana-de-açúcar usada como ração do gado no período de seca. O projeto inclui a construção de um laticínio próprio, o qual já deveria ter sido entregue (há três anos), mas em função de uma aparente falta de planejamento, não se efetivou. Enquanto ele não sai, a EC se encarrega de levar o leite para um laticínio na cidade de Parauapebas.

As vacas foram entregues em 2008 antes da criação da estrutura adequada. Entregue junto das matrizes, segundo os entrevistados, o dinheiro para os currais foi desviado (informação verbal) 9 e ainda resta construir 37 currais, além do laticínio. Os idealizadores do projeto previram que as vacas forneceriam de 10 a 15 litros de leite diariamente, entretanto a produção não passa dos cinco litros. Assunto controverso, os produtores questionam a qualidade das vacas, enquanto os idealizadores alegam que elas são adaptadas ao clima do Pará e questionam a capacidade dos produtores em fazerem o manejo adequado. Houve curso de manejo, mas

7 Segundo Cleber Frutuoso, presidente da Estação Conhecimento, consideraram-se a vocação da área para receber o projeto e o histórico dos produtores na região, assim como seu interesse e empenho.

8 Art. 22-A. O Poder Público poderá, ressalvadas as atividades agropecuárias e outras atividades econômicas em andamento e obras públicas licenciadas, na forma da lei, decretar limitações administrativas provisórias ao exercício de atividades e empreendimentos efetiva ou potencialmente causadores de degradação ambiental, para a realização de estudos com vistas na criação de Unidade de Conservação, quando, a critério do órgão ambiental competente, houver risco de dano grave aos recursos naturais ali existentes. A UC não possui Plano de Manejo para regular as atividades (Brasil, 2000).

9 Informação fornecida por entrevistados no dia 21 de fevereiro de 2013, dentro da EC. 
ainda assim não se atingiu o esperado e os produtores reclamam da qualidade e efetividade dos cursos. Tal problemática demonstra a tensão existente dentro da APA entre os atores, fato que pode dificultar o avanço das atividades na região.

Os beneficiários recebem suporte contínuo e em contrapartida devem devolver uma bezerra fêmea por ano durante dez anos, que são vendidas e o dinheiro revertido para a EC em beneficio de toda a comunidade.

$\bigcirc$ projeto de bovinocultura é importante, pois representa um incremento à renda dos produtores. A construção do laticínio significa agregação de valor ao leite em aproximadamente $50 \%$ pela produção de produtos derivados do leite. Entretanto, esse precisa ser complementado por outros projetos. Envolveu apenas 53 produtores da APA.

Mesmo pensada sustentável, é preciso questionar a função de bovinocultura dentro de uma APA. Segundo Arima, Barreto e Brito (2005), produção pecuária não é compatível com conservação ambiental. Além de ter potencial impactante ao meio, a cultura bovina afasta cada vez mais os produtores da agricultura, cuja produção já é crítica na região.

Alguns produtores obtiveram tanto sucesso com a bovinocultura que abandonaram a agricultura, e embora muitos se sintam seduzidos pela pecuária, pela possibilidade de ascender e pelo status que ela representa, essa ainda não é uma tendência na APA. Mas pode vir a ser, especialmente porque a maioria dos moradores da APA são ex-garimpeiros e podem ser mais fortemente atraídos pela pecuária. Além disso, de acordo com relatos dos produtores, quando houve reuniões na EC para optarem por um projeto, a Fundação Vale, idealizadora do projeto, fez grande propaganda da vantagem econômica da bovinocultura, inclusive declarando que cada produtor conseguiria comprar uma caminhonete Hilux em um ano (informação verbal). 10

Existe um projeto de fruticultura que inclui o estímulo às culturas de cupuaçu, banana, açaí, limão e laranja e a construção de um Packing House ${ }^{11}$ para recolher, centralizar a produção e operacionalizar a distribuição, mas ele ainda não tinha sido operacionalizado.

De acordo com Manoel Delva, gestor da APA, haverá incentivo aos SAF para recuperação e recomposição da Reserva Legal, já que estes também são considerados Reserva Legal pela Lei n. 12.651, de 25 de maio de 2012. Quando a Reserva Legal passou de 50\% a 80\%, em 1996 (Brasil, 1996), não houve nenhuma medida de recuperação exigida pelo Ibama e, depois de 2012, embora exista a cobrança de recuperá-la, não há auxilio nem suporte técnico para tal (informação verbal). ${ }^{12}$ Portanto, nesse contexto, o projeto de fruticultura é muito relevante.

No âmbito da produção agrícola, os estímulos da EC se concentram no fornecimento de adubação por compostagem, e ocasionalmente insumo, e no transporte dos produtores para a feira de Carajás. Além disso, esta Oscip fornece cinco técnicos agropecuários, um para cada núcleo da APA, que fazem visitas rotineiras e tratam problemas pontuais, dois agrônomos, que fazem análise de solo e tratam problemas mais complexos, um zootecnista e um veterinário para fazer partos.

10 Informação fornecida por Raimundo de Paula e Nelson Bezerra, respectivamente presidente e tesoureiro da Aproapra, em entrevista realizada no dia 21 de fevereiro.

11 Packing House é o lugar (galpões no núcleo da Estação Conhecimento) onde se organiza toda a produção (frango, leite etc.), embalando-a e encaixotando-a para comercialização. Esse modelo foi criado pela Vale. A associação defende outra visão: a da escola que ensina o cidadão a plantar, a cuidar da horta, a cuidar do pomar, a cuidar das galinhas, a cuidar do gado e a fazer uma boa cerca, além do viveiro de mudas para recuperar. A associação já começa a ganhar dinheiro vendendo para o próprio núcleo as mudas para reflorestar as áreas que precisam ser recuperadas.

12 Informação fornecida por Manoel Delva, gestor da APA, em entrevista realizada no dia 20 de fevereiro. 


\section{Prefeitura Municipal de Parauapebas}

A prefeitura atua na região via Sempror e tem como foco a criação de condições favoráveis para fixar o produtor e a redução dos custos de produção para torná-la mais barata e acessível à população, visando reduzir a vulnerabilidade do abastecimento da cidade.

A atuação da Sempror permanece centrada em alguns pontos, em sua maioria já evidenciados pelo Duramaz-1: estabelecimento de parcerias e convênios de estímulo ao desenvolvimento local, dando respaldo aos mesmos, contribuição à logística do escoamento da produção ao mercado municipal por meio do fornecimento de transporte e da "Casa de Apoio aos Produtores", programa de mecanização gratuita das terras, importante iniciativa para conter o desmatamento e queimada de novas áreas para cultivo, fornecimento do corpo profissional para assistência técnica.

Além da atuação da Sempror, a prefeitura fornece transporte para os funcionários, os recursos humanos (professores e administrativos) da escola e do posto de saúde da APA.

\section{Os projetos, os conflitos e a sustentabilidade na APA: análise e discussão}

Segundo o Duramaz-1, a experiência de desenvolvimento sustentável da APA está atrelada principalmente à criação da Cooper, abordada anteriormente, e ao desenvolvimento do Padeq, apresentado e analisado a seguir.

\section{Padeq}

$\bigcirc$ advento do Padeq contribuiu para a constatação pelo Duramaz-1 de que a sustentabilidade local existe, entre outros - mas principalmente -, em função dos estímulos ao extrativismo florestal não madeireiro e aos SAF.

Gerenciado pelo Ministério do Meio Ambiente com apoio da Vale, da Cooper e da Sempror, o Padeq foi iniciado em 2005 e teve como objetivo reduzir as queimadas via inserção e suporte à mecanização agrícola para o desenvolvimento da agricultura familiar, além de desenvolver a apicultura, os SAF e o extrativismo florestal não madeireiro.

Os SAF de fruticultura nativa e o extrativismo florestal não madeireiro são formas de uso sustentável do solo para a agrossilvicultura, sendo este uma forma de exploração dos recursos florestais por meio da conservação da floresta em pé, enquanto os SAF consistem em sistemas de uso integrado da terra, com uso eficiente dos recursos naturais e otimização dos efeitos benéficos das interações entre os componentes do meio, possibilitando elevada produtividade associada à proteção ambiental (Altieri, 2012).

projeto beneficiou 23 famílias, das quais apenas cinco eram da APA, selecionados por critérios vagos.

Em nível de organização social, a rivalidade entre os membros da agricultura familiar é palpável [...] a coesão da comunidade sofre com algumas dificuldades, principalmente por causa das regras de execução dos diversos projetos locais. Estes interessam quase sempre as mesmas pessoas, os membros da Cooper e seus próximos, que começam a criar tensão no seio da Aproapa. É verdade que 
os critérios de seleção nem sempre são transparentes e que os mais merecedores, ambientalmente falando, nem sempre são incluídos nesses programas (Le Tourneau; Droulers, 2010, p. 99).

Afirmam os autores que os líderes de projetos sempre tendem a favorecer o mesmo grupo de pessoas: afiliados da Cooper e aqueles recomendados por eles. A situação é recorrente ainda hoje.

$\bigcirc$ Padeq foi a medida inicial para atingir a meta de desmatamento e queimada zero e, em vigor desde 2005, tinha perspectivas de expansão aos demais produtores, de modo que o dispositivo de mecanização de terrenos, inicialmente garantido aos membros do Padeq, foi estendido ao resto da comunidade. Hoje, ocasionalmente ocorrem queimadas acidentais, e é muito raro os agricultores queimarem para produzir, pois, se o fazem, são penalizados pela exclusão de benefícios como a mecanização da terra, a inclusão em projetos e a participação em cursos promovidos na EC.

$\bigcirc$ estabelecimento da mecanização como alternativa à derrubada e queimada gerou insatisfação dos produtores que apontam elevada redução da produtividade. Para eles, a produção responde melhor à queima do que à mecanização isolada, e isso de fato acontece, já que a queimada disponibiliza nutrientes no solo incorporados pelas culturas. Como era necessário um insumo a mais, a Vale, por meio da Gerência de Meio Ambiente, passou a ofertar adubação, mas a iniciativa ainda é muito incipiente e não abrange a totalidade dos agricultores, e os produtores estão se articulando e levantando a possibilidade de apoio da Sempror na adubação. Cabe ressaltar que a adubação por compostagem tem sido insuficiente para elevar a produtividade e os produtores almejam adubação química, contrária à prática de agricultura sustentável. A proibição estrita à queimada e à derrubada e a introdução da mecanização apontam os limites tanto da sustentabilidade da produção agrícola como da produtividade e da proteção do meio ambiente dentro da APA.

Tendo em vista a propensão dos jovens, agricultores ou não, em deixar a área rural, parte dos recursos do Padeq foram utilizados para treiná-los em apicultura, pesca, produção agroecológica, considerado um fator importante para despertá-los e estimular sua manutenção no campo.

Encerrado no ano de 2008, dentro do prazo estipulado, o Padeq objetivou tornar os produtores autônomos, mas aparentemente não conseguiu. Ao encerrar, o projeto passou a continuidade e manutenção das atividades para a responsabilidade dos produtores e entregou duas roçadeiras, uma motosserra, uma moto e um viveiro com mudas, deixando-lhes as ferramentas necessárias. No entanto, os produtores beneficiados não se apropriaram das mesmas e esperaram intervenção da Aproapra para a criação de uma parceria com a prefeitura para a manutenção dos SAF, mas a nova direção da associação não se envolveu e os produtores não conseguiram se unir nem se organizar, de modo que a atividade se encerrou. De acordo com os produtores, havia uma rixa interna no seio da Aproapra, e os não beneficiados viam os demais como um grupo rival. Esse fato mostra a falta de coletividade e união dos produtores dentro da APA.

Apesar do ocorrido, após o término do Padeq, a Cooper deu continuidade aos SAF criados por ele. Isso foi feito apenas com os produtores associados à cooperativa, beneficiados ou não pelo programa, expandindo-o. Além do auxilio e suporte fornecido pela cooperativa, ela 
estabeleceu uma parceria com a Fecat e a Petrobras e criou um programa de fruticultura com o sistema agroflorestal cujo objetivo foi estimular o interesse dos jovens, envolvendo os filhos dos produtores, dos quais seis eram da APA.

É relevante a organização da Cooper e o seu papel no estabelecimento de práticas agrícolas sustentáveis, no entanto o favorecimento de um grupo de pessoas levanta questionamentos da comunidade.

Enquanto um pequeno grupo obtém êxito na produção agrícola sustentável pelos SAF e pelo extrativismo florestal não madeireiro, a maioria dos moradores da APA se vê privada de tais iniciativas, seja por desinteresse de se associar à cooperativa, seja por dependência e falta de empoderamento, exclusão ou dificuldade financeira, reduzindo a possibilidade de ampliação da sustentabilidade pautada nessas técnicas.

As outras iniciativas também são relevantes, a exemplo dos projetos desenvolvidos pela EC, que deixou de lado a agricultura e os SAF de frutas nativas para concentrar-se no projeto de bovinocultura voltado para a produção de leite, para dar autonomia à produção de queijo e outros derivados e tornar os produtores independentes e sustentáveis.

$\bigcirc$ Padeq sintetiza bem o problema de falta de autonomia e empoderamento dos produtores para agirem em seu benefício, de dependência e assistencialismo presentes na APA. Diversos projetos começam e terminam sem tornar os produtores autônomos e independentes, sendo um requisito essencial o devido acompanhamento e orientação para tal.

Mesmo a EC, que procura estimular a autonomia e independência do produtor, encontra deficiências. No projeto de bovinocultura, foi fornecido material para a cerca elétrica e, em contrapartida, os próprios produtores deveriam montá-la; entretanto, houve produtor que não o fez, e não houve penalização.

Muito do trabalho realizado demonstra um caráter assistencialista. Por outro lado, os próprios produtores se mostram desinteressados de cumprir o que lhes cabe, mesmo sendo uma parte muito simples, como no caso da cerca no projeto de bovinocultura. Todos os atores locais, inclusive alguns produtores, alegam forte dependência paternalista por parte dos produtores da APA, em que eles são dominados por necessidade, vontade ou consentimento. Isso ocorre por uma falta de capacidade e empoderamento, mas também pela falta de interesse e pelo comodismo. Acomodados na situação em que se encontram, têm pouca motivação para fazer por eles, buscando sempre receber.

O histórico da Vale na região e a ação repressiva do Estado para remover a população de Serra Pelada na época de sua instalação em Carajás traz uma relação conflituosa com a população local, que ainda hoje se sente injustiçada e busca o tempo todo receber benefícios. A isso se soma o fato de muitos produtores da APA serem ex-garimpeiros ou ex-funcionários da Vale, ampliando a situação de dependência. Por outro lado, a Vale parece sustentar essa situação tomando-a não somente parte de sua obrigação como empresa socialmente responsável, igualmente uma ação de controle social e manutenção da ordem na região. $\bigcirc$ controle social é importante na medida em que mantêm a ordem e a integração social necessários ao desenvolvimento da sociedade (Durkheim, 1978), entretanto tal controle social exercido pela Vale se traduz numa prática de exercício de poder e dominação, apesar de contribuir positivamente para o desenvolvimento local. $\bigcirc$ papel de agente que a Vale exerce no desenvolvimento local reduziria esse controle em face à população? 


\section{A percepção da sustentabilidade: indicadores}

As experiências estudadas no Duramaz-1 tiveram sua sustentabilidade medida por meio de um sistema próprio de indicadores. Para a APA Igarapé Gelado, os indicadores com melhor pontuação e, portanto, mais significativos para estabelecer a sustentabilidade local foram dinâmicas do meio ambiente (módulo proteção do meio ambiente), inserção nos circuitos econômicos e práticas de higiene e saúde (ambos no módulo condições de vida), como observado na Figura 1 que traz o resultado gráfico dos 14 indicadores para a APA.

É importante retomar as observações feitas a respeito desses indicadores relacionando-as às respostas obtidas nas entrevistas realizadas com os produtores e demais atores locais.

\section{Figura 1 - Indicadores para a APA Igarapé Gelado}

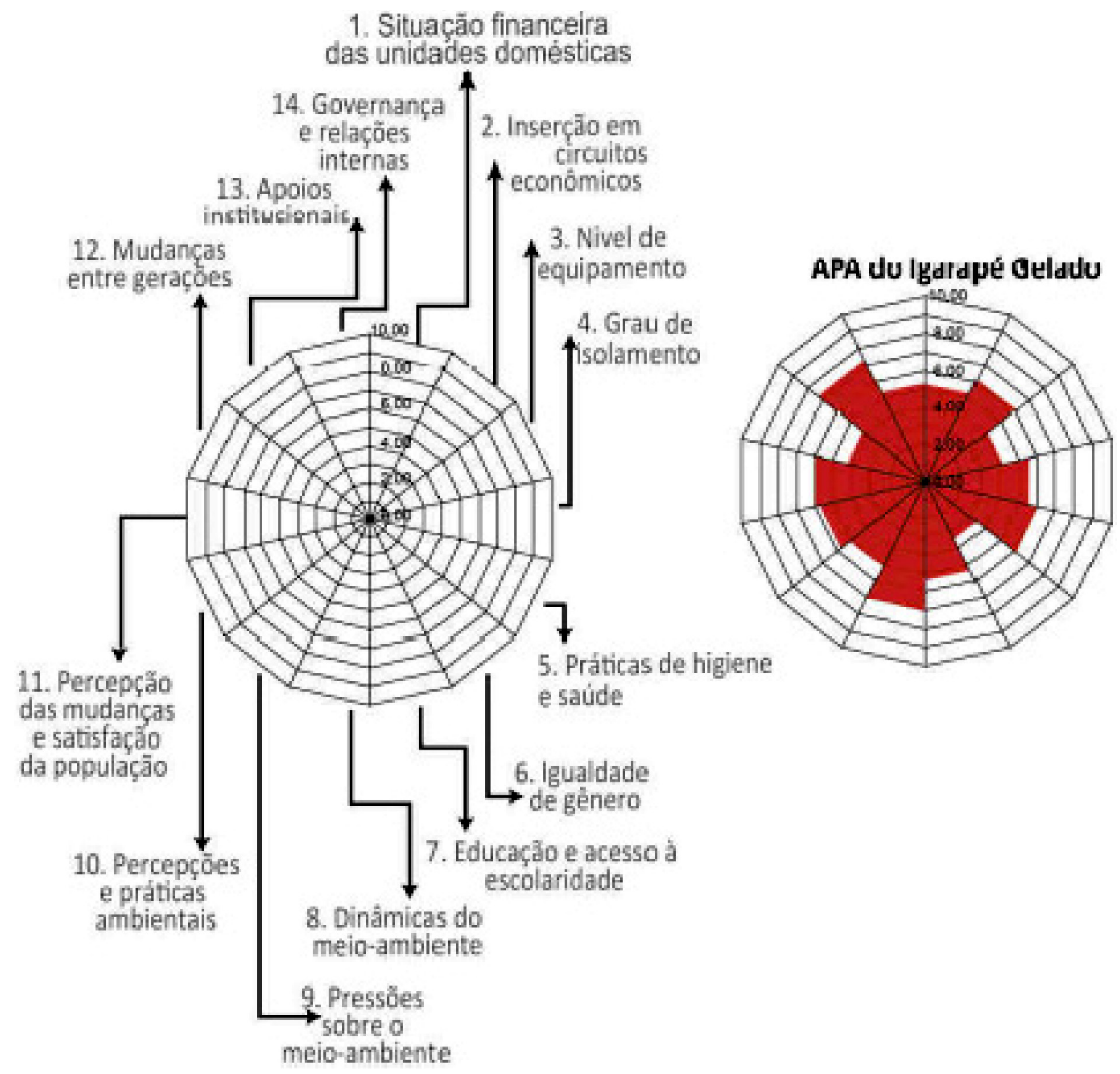

fonte: Droulers et al. (2012, p. 175). 


\section{Inserção econômica}

A inserção econômica considera a complexidade dos mercados, a diversidade das atividades produtivas, a vulnerabilidade da economia, a utilização de mão de obra exterior e a monetarização da produção. A maioria dos programas de desenvolvimento viabiliza economicamente uma prioridade, entretanto, alguns consideram que ela pode ser perniciosa. Para o Duramaz-1, a viabilização econômica passa pela inserção em circuitos mais diversificados e de fontes de renda menos vulneráveis, sendo a diversificação do mercado, da produção e das estratégias de venda as formas de evitar a desestruturação da comunidade.

Segundo o Duramaz-1, a APA inseriu-se nos circuitos econômicos via apoio da Vale e da prefeitura as quais asseguram o transporte gratuito e o estabelecimento das feiras, mercados atrativos. $\bigcirc$ mesmo fato se verificou também em 2013 quando do trabalho de campo, entrevistas realizadas e documentos consultados.

subindicador complexidade dos mercados adota uma escala de pontuação para o destino da produção segundo as seguintes estruturas de mercado: atravessador, mercado municipal, venda direta, cooperativa e comércio solidário. Essa escala aponta a Cooper como a melhor estrutura de venda, porém atualmente, diante do contexto e das especificidades da APA parece ser o atravessador e o mercado municipal as melhores estruturas de venda e não mais a cooperativa. Não vender a produção nos circuitos econômicos, para a Cooper, não significa necessariamente menor inserção econômica, conforme evidenciado anteriormente.

Em 2009, a Cooper exercia um papel importante na redução da vulnerabilidade, por garantir a compra a preço fixo, comprar as perdas de produção como medida de estímulo e contribuir para a redução da dependência da produção ao mercado municipal. No contexto atual, tais atributos perdem relevância e não se sustentam mais, visto a chegada de novos habitantes na região e a consequente ampliação do mercado consumidor.

\section{Práticas de higiene e saúde}

subindicador prática de higiene e saúde diz respeito ao tratamento de água para consumo doméstico, ao acesso às estruturas de saneamento básico e ao estado da saúde pública, de acordo com as doenças mais frequentes.

Mesmo a comunidade não tendo um posto de saúde em 2007, havia um grau de organização local para visitas regulares ao médico. Quanto ao tratamento de água, boa parte dos moradores entrevistados possuía poço artesiano, indicando o uso de filtros ou de cloro para purificar a água dos rios, graças a esforços desenvolvidos conjuntamente pela prefeitura de Parauapebas e a Vale (Le Tourneau; Droulers, 2010). Durante pesquisa realizada em campo, a utilização de cloro no tratamento de água foi uma resposta predominante entre os 23 entrevistados.

\section{Dinâmicas do meio ambiente}

Sinteticamente, o indicador dinâmicas do meio ambiente considera o estado de desmatamento da área estudada e da zona tampão (segundo dados do Prodes), o respeito às áreas de preservação permanente (APP) e as dinâmicas da paisagem e da biodiversidade. A APA foi considerada uma das zonas mais preservadas da pesquisa e a aposta em SAF e na comercialização da produção foram apontadas como o caminho da sustentabilidade local. 
Cabe aqui ressaltar que, na época de criação da APA, estava em vigor a Lei Federal n. 4.771/1965, que estabelecia 50\% de Reserva Legal (área da propriedade que deve ser mantida com vegetação original), valor que o Duramaz-1 tomou como referência, fazendo a APA parece ser mais conservada do que de fato é.

\section{Considerações finais}

$\bigcirc$ foco deste estudo foi a análise do papel dos atores regionais na sustentabilidade da agricultura da APA Igarapé Gelado, tomando como base os resultados do Duramaz-1 e estudos anteriores (Le Tourneau; Droulers, 2010; Marchand, 2010). Identificou-se um quadro diferente do encontrado em 2009, quando os atores tinham funções diferentes das atuais, com relações modificadas e diferentes influências na sustentabilidade da atividade. Atualizaram-se alguns dados, a partir dos quais se avaliou a experiência de sustentabilidade local.

Do total de 16 atores que influenciam a dinâmica local e regional, os considerados mais relevantes pelo Duramaz-1 e pela presente pesquisa, são a Cooper, a Vale e a Prefeitura Municipal de Parauapebas. Além dos atores de relevância, o Duramaz-1 indica dois projetos imperativos para sustentabilidade da APA: a consolidação das condições de atuação da Cooper e o advento do Padeq. Ambos indicam a aposta na produção e comercialização de polpas congeladas de frutos em SAF, mas o alcance do primeiro é limitado, incidindo num pequeno grupo de produtores dentro da APA (10\% dos produtores da APA são associados à Cooper), ao passo que, no segundo, a substituição das queimadas pela mecanização da produção em função da falta de organização, articulação e empoderamento, promoveu a descontinuidade das ações. Esse fato sintetiza tanto a carência de autonomia como a existência de uma cultura assistencialista dentro da APA, também assinalada pelos atores e por alguns produtores locais.

O Padeq foi bem-sucedido na mecanização das terras em substituição às queimadas para o preparo do solo para a fruticultura. Entretanto, após a mecanização, os produtores passaram a solicitar a introdução de adubos químicos. Assim, tal medida é questionável para estabelecer uma produção sustentável e representa riscos ao meio ambiente.

Ao concentrar forte poder político e econômico na região, a Vale influencia a dinâmica local e praticamente substitui o aparato estatal em alguns aspectos no que tange à gestão da APA, sendo responsável, junto com a prefeitura, pelo fornecimento de recursos, logística e infraestrutura. Além disso, segundo o Duramaz-1, a Vale é importante por estar envolvida na criação do Padeq e do Projeto Açaí, uma compensação ambiental com a qual os produtores não se comprometeram. Por outro lado, a empresa poderia se restringir a responder por seus erros, mas ela é constantemente solicitada a apoiar iniciativas diversas, às quais responde, pois the interessa sobretudo seu enquadramento nas normas de responsabilidade socioambiental.

Além dessas atuações limitadas, a Fundação Vale teve uma iniciativa relevante quando criou a EC, com o apoio da prefeitura, via Sempror, para fomentar o desenvolvimento local com foco na produção e na educação. Sua principal iniciativa foi o projeto de bovinocultura, relevante por representar um incremento de renda, mas antagônico, pois concorre para afastar cada vez mais os produtores das atividades de plantio. 
A Cooper, principal ator regional, deveria estimular o extrativismo e a produção de frutas regionais em SAF e reduzir a variação de preços, a dependência e a vulnerabilidade da produção. Os dois primeiros pontos se mantiveram, mas a cooperativa deixou de ser relevante na segurança financeira e econômica, pois tal atividade perdeu a função diante do estabelecimento de um vasto mercado consumidor local.

A grande relevância da Cooper é também por representar um espaço altamente organizado e articulado com os demais atores regionais e propiciar maior organização, articulação, autonomia e empoderamento dos produtores.

Em suma, verifica-se que os indicativos da sustentabilidade da agricultura da APA em 2009 se modificaram no contexto atual, tanto no que diz respeito à atuação de cada ator quanto à função dos projetos existentes. Apenas um pequeno grupo obtém êxito na produção agrícola sustentável pelos SAF e pelo extrativismo florestal não madeireiro; a maioria dos moradores da APA não se beneficia de tais iniciativas, seja por desinteresse ou por dependência, falta de empoderamento, exclusão e dificuldade financeira, reduzindo a possibilidade de ampliação da sustentabilidade pautada em tais técnicas.

\section{Referências}

ALTIERI, M. Agroecologia: bases científicas para uma agricultura sustentável. São Paulo/ Rio de Janeiro: Expressão Popular/AS-PTA, 2012.

AQUINO, M. J. S. O ferro e a "canga": disputas e parcerias na conservação e exploração mineral em Carajás. In: ENCONTRO DA ANPPAS, 3., 23-26 maio 2006, Brasilia. Anais... Brasília, 2006.

ARIMA, E.; BARRETO, P.; BRITO, M. Pecuária na Amazônia: tendências e implicações para a conservação ambiental. Belém: Instituto do Homem e do Meio Ambiente da Amazônia, 2005.

BRASIL. Presidência da República. Casa Civil. Lei n. 9.985, de 18 de julho de 2000. Regulamenta o Art. 225, § 1ㄴ, incisos I, II, III e VII da Constituição Federal, institui o Sistema Nacional de Unidades de Conservação da Natureza e dá outras providências. Disponível em: <http://www.mma.gov.br/port/conama/legiabre.cfm?codlegi=322>. Acesso em: 22 nov. 2016.

BRASIL. Presidência da República. Subchefia para Assuntos Jurídicos. Medida Provisória n. 1.511, de 25 de julho de 1996. Disponível em: <http://www.planalto.gov.br/ ccivil_03/mpv/Antigas/1511.htm>. Acesso em: 22 nov. 2016.

COSTA, J. M.; HIRT, C. Repercussões territoriais das ações públicas e privadas na Amazônia Oriental. Revista Geográfica de América Central, San José, v. 2, p. 1-16, 2011.

DROULERS, M. et al. Um sistema de indicadores de desenvolvimento sustentável na Amazônia. Sustentabilidade em Debate. Brasília, v. 2, n. 1, 2001. Disponível em: <http://seer.bce.unb.br/index.php/sust/article/viewArticle/3916>. Acesso em: 17 mar. 2012.

DURKHEIM, E. As regras do método sociológico. São Paulo: Abril Cultural, 1978. (Coleção Os Pensadores.) 
FUNDAÇÃO VALE. Um olhar sobre Parauapebas: diagnóstico socioeconômico. Disponível em: <http://www.fundacaovale.org/pt-br/a-fundacao-vale/como-atuamos/ Documents/estrada-de-ferro-carajas/livreto_Parauapebas_Par\%C3\%Al.pdf>. Acesso em: 25 mar. 2012.

IBGE. Infográfico da evolução populacional de Parauapebas. Disponível em: <http:// www.ibge.gov.br/cidadesat/painel/painel.php?codmun=150553Esearch=para $\mid$ paraua pebas\#historico>. Acesso em: 11 set. 2013.

LETOURNEAU, F.-M.; DROULERS, M. (Dir.). L'Amazonie brésilienne et le développement durable. Paris: Belim, 2010.

MARCHAND, G. Un système d'indicateurs pour évaluer les impacts territoriaux des politiques de développement durable dans les zones rurales d'Amazonie brésilienne: l'expérience Duramaz. Tese (Doutorado em Geografia, Desenvolvimento e Urbanismo) - Université Sorbonne Nouvelle - Paris 3, Paris, 2010.

MELLO-THÉRY, N. A.; THÉRY, H. Carajás-Parauapebas: conflitos entre modelos de desenvolvimento na Amazônia Oriental. Revista Praia Vermelha, Rio de Janeiro, v. 19, n. 2, p. 73-88, 2009. Disponível em: <http://200.144.190.38:8180/xmlui/handle/1/177>. Acesso em: 17 mar. 2012.

MELLO, N. A.; VAN TILBEURGH, V. A proteção da floresta amazônica: políticas de Estado, percepção dos atores e gestão dos espaços locais. In: ENCONTRO NACIONAL DA ANPEGE, 8., set. 2009, Curitiba. Disponível em: <http://hal.archives-ouvertes. $\mathrm{fr} /$ docs/00/45/70/07/PDF/Anpege_Duramaz_Neli_e_Veronique_final.pdf>. Acesso em: 20 mar. 2012.

MONTEIRO, M. A.; COELHO, M. C. N. As políticas federais e reconfigurações espaciais na Amazônia. Novos Cadernos Naea, v. 7, n. 1, p. 91-122, jun. 2004. Disponível em: <http://www.periodicos.ufpa.br/index.php/ncn/article/viewFile/38/32>. Acesso em: 19 jun. 2013.

MUCHAGATA, M. G. O papel das organizações de agricultores nas transformações recentes do uso do espaço em região de fronteira amazônica: o caso da região de Marabá. In: SAYAGO, D.; TOURRAND, J. F; BURSZTYN, M. Amazônia: cenas e cenários. Brasilia: Universidade de Brasilia, 2004.

SANTOS, R. F. Planejamento ambiental: teoria e prática. São Paulo: Oficina de Textos, 2004.

SIMIONI, F. J. et al. Lealdade e oportunismo nas cooperativas: desafios e mudanças na gestão. Revista de Economia e Sociologia Rural, Brasilia, v. 47, n. 3, p. 739-765, set. 2009. Disponível em: <http://www.scielo.br/pdf/resr/v47n3/v47n3al0.pdf>. Acesso em: 22 nov. 2016.

SNUC. Sistema Nacional de Unidades de Conservação. Texto da Lei n. 9.985, de 18 de julho de 2000, e vetos da presidência da República ao PL aprovado pelo Congresso Nacional. 2. ed. ampl. São Paulo: Conselho Nacional da Reserva da Biosfera da Mata Atlântica, 2000. Disponível em: <http://www.rbma.org.br/rbma/pdf/Caderno_18_2ed.pdf>. Acesso em: 22 nov. 2016. 